\title{
Singlet Excited States of Anions with Higher Main Group Elements
}

\author{
Ryan C. Fortenberry \\ rfortenberry@georgiasouthern.edu \\ Department of Chemistry, Georgia Southern University, Statesboro, GA 30460, U.S.A.
}

May 25, 2022

Received — 


\begin{abstract}
Previous studies have shown that dipole-bound excited states exist for certain small anions. However, valence excited states have been reported for some closed-shell anions, but those with singlet valence excited states have, thus far, contained a single silicon atom. This work utilizes high-level coupled cluster theory previously shown to reproduce excited state energies to better than 0.1 $\mathrm{eV}$ compared with experiment in order to examine the electronic excited state properties of anions containing silicon and other higher main group atoms as well as their first row analogues. Of the fourteen anions involved in this study, nine possess bound excited states of some kind: $\mathrm{CH}_{2} \mathrm{SN}^{-}, \mathrm{C}_{3} \mathrm{H}^{-}, \mathrm{CCSiH}^{-}, \mathrm{CCSH}^{-}$, $\mathrm{CCNH}_{2}^{-}, \mathrm{CCPH}_{2}^{-}, \mathrm{BH}_{3} \mathrm{PH}_{2}^{-}, \mathrm{AlH}_{3} \mathrm{NH}_{2}^{-}$, and $\mathrm{AlH}_{3} \mathrm{PH}_{2}^{-}$. Two possess clear valence states: $\mathrm{CCSiH}^{-}$and its first row analogue $\mathrm{C}_{3} \mathrm{H}^{-}$. Substantial mixing appears to be present in the valence and dipole-bound characters for the first excited state wavefunctions of many of the systems reporting excited states, but the mixing is most pronounced with the ammonia borane-like $\mathrm{AlH}_{3} \mathrm{NH}_{2}^{-}$, and $\mathrm{AlH}_{3} \mathrm{PH}_{2}^{-}$anions. Inclusion of second row atoms in anions whose corresponding radical is strongly dipolar increases the likelihood for the existence of excited states of any kind, but among the systems considered to date with this methodology, only the nature of group 14 atoms in small, closed-shell anions has yet been shown to allow valence singlet excited states.
\end{abstract}

Keywords: anions - electronically excited states - valence excited states dipole-bound states - coupled cluster theory 


\section{Introduction}

In the search for carriers of unexplained interstellar absorption spectra, the electronic properties of rarely studied systems offer a viable new avenue of research to explore. The set of as-of-yet unexplained visible to near-infrared peaks known as the diffuse interstellar bands (DIBs), for example, has remained a mystery for nearly a century (Sarre 2006). However, it has been suggested that anions may be responsible for some of the DIB features (Sarre 2000; Cordiner \& Sarre 2007). Recent work has shown a relative richness of electronic absorption features below the electronic binding energy (eBE) (Simons 2008, 2011) for some anions that exhibit singlet dipole-bound excited states and even some species that appear to possess additional valence excitations (Fortenberry \& Crawford 2011b a) For any dipole-bound anion, the corresponding radical must possess large a dipole moment (Fermi \& Teller 1947; Turner \& Fox 1966; Coulson \& Walmsley 1967; Crawford \& Dalgarno 1967; Jordan \& Luken 1976; Turner 1977; Crawford \& Garrett 1977; Gutowski et al. 1996; Wang \& Jordan 2002; Jordan \& Wang 2003) in order for the electron to remain bound within the system. In an ideal situation the dipole moment must be at least greater than $1.625 \mathrm{D}$ (Fermi \& Teller 1947; Turner \& Fox 1966; Coulson \& Walmsley 1967) and probably closer to 2.5 D Cordiner \& Sarre 2007; Gutsev \& Adamowicz 1995; Ard et al. 2009) typically in a highly diffuse orbital (Mead et al. 1984). However, valence ground and excited states may exist below the single dipole-bound state which functions as the upper excitation energy limit since the dipole-bound state excitation energy must be nearly coincident with the eBE (Simons 2008).

"Bound excited valence states in molecular anions are rare" (Brinkman et al. 1993). However, some anions are known to exhibit valence electronic excitations, but most of these are open-shell anions where excitations do not have to overcome the additional energy barrier of sorts involved in splitting an electron pair while still remaining below the eBE. 
Negatively charged small fragments or atoms (Brinkman et al. 1993) and, especially, carbon chains (Maier 1998; Jochnowitz \& Maier 2008; Zhoa et al. 2009) have been documented to possess bound valence excited states. Additionally, some anions, including many with second row atoms, are known to possess triplet excited states above the ground state (Meloni et al. 2004; Pino et al. 2004; Sheehan et al. 2008; Inostroza \& Senent 2010) where the energy splitting between the ground state (which may either be singlet or triplet) and the triplet excited state is relatively small. Much larger anions are also known to possess excited states, (Brinkman et al. 1993; Skurski \& Gutowski 2000; Sobczyk et al. 2003) and such behavior is relevant to the study of many biological species (Chen \& Chen 2001). However, a new set of small, closed-shell singlet anions have been studied previously for their electronic properties (Fortenberry \& Crawford 2011b a). They represent an emerging class of anions that are not: 1) large, long, or exotic, 2) atomic, elemental, or diatomic, or 3) radical, diradical, or open-shell. They are closed-shell anions of three to seven atoms (with no more than four heavy atoms) that are composed of common substituent groups.

Silicon is present in each of the small singlet systems where previous study indicates the existence of valence excited states (Fortenberry \& Crawford 2011ba). Silicon and other higher row main group elements are well-known to have very different bonding environments than their more common C, O, and N (first row) analogues (Kutzelnigg 1984; Driess \& Grützmacher 1996; Power 1999; Brown \& Borden 2000; Owens et al. 2006; Woon \& Dunning 2009, 2010, 2011). Silicon provides many unexpected differences in the molecular structures as compared to carbon molecules of the analogous chemical formula including the butterfly conformer of $\mathrm{Si}_{2} \mathrm{H}_{2}$ and cyclic $\mathrm{Si}_{3}$ (Li et al. 1995; Chesnut 2002; Reilly et al. 2012). Steric effects from the presence of the larger $n=3$ orbitals in the higher row atoms inhibit standard valence bond $s p^{3} / s p^{2}$ hybridization or electron pair recoupling (Woon \& Dunning 2011) making molecules containing these atoms "reluctant to hybridize" (Kutzelnigg 1984; Driess \& Grützmacher 1996; Owens et al. 2006). The lack of 
hybridization is most extreme in second row atoms, most notably for silicon, which forms strong $\sigma$ bonds due to an increase in its inclusion of the $s$-type atomic orbitals (Power 1999 Brown \& Borden 2000; Owens et al. 2006). Hence, silicon is even less likely to create bonds of significant hybridized character than its rowmates phosphorus and sulfur. The increase in $s$ character is most straightforwardly observed in ${ }^{1} A_{1} \mathrm{SiH}_{2}$ where the optimal bond angle is $92.1^{\circ}$, (Dubois 1968; Driess \& Grützmacher 1996) much closer to $90^{\circ}$ than $102^{\circ}$, which the bond angle for singlet carbene (Bourissou et al. 2000). Even so, the carbene carbon here exibits similar effects since the bond angles in both ${ }^{1} A_{1} \mathrm{CH}_{2}$ and $\mathrm{SiH}_{2}$ are much less than the $120^{\circ}$ bond angle expected for standard $s p^{2}$ hybridized atoms (Woon \& Dunning 2011).

The previous work examining the singlet excited states of the aforementioned small, closed-shell anions (Fortenberry \& Crawford 2011b) employed coupled cluster methods to reproduce the experimental eBEs and the lone dipole-bound state excitation energies of $\mathrm{CH}_{2} \mathrm{CN}^{-}$(Sarre 2000; Cordiner \& Sarre 2007, Lykke et al. 1987) and $\mathrm{CH}_{2} \mathrm{CHO}^{-}$(Mead et al. 1984; Mullin et al. 1992, 1993) to within $0.06 \mathrm{eV}$ or better. The same accurate methodology was extended to provide likely dipole-bound and valence excited states of other anions for which experiments have not yet been performed. The present study employs the same methodology and is an examination of the excited state properties of similar molecular anions containing the second row elements aluminum, silicon, phosphorus, and sulfur and how they relate to their first row analogues. Some systems analyzed have been constructed to produce structures related to those where the previous computational studies indicate the presence of dipole-bound and valence excited states for silicon-containing species (Fortenberry \& Crawford 2011b a). Other anions of interest to this work are unique attempts to find if the larger atoms play a role in the stabilization of valence excitations below the eBE. The search for dipole-bound states provides motivation for analysis of these types of systems, but the search for even rarer valence states offers a more fascinating result. It is currently unknown how anions may affect attribution of the DIBs, but the probable 
existence of excited states for previously unexamined molecules may hold some new insight into this near-century-old problem.

\section{Computational Details}

Coupled cluster theory is one of the most accurate quantum chemical methods developed to date, (Helgaker et al. 2004; Lee \& Scuseria 1995; Shavitt \& Bartlett 2009) and our past (Fortenberry \& Crawford 2011b a) and current computations of excited states of anions exclusively utilize this method extensively. The geometries are optimized at the coupled cluster singles, doubles, and perturbative triples level [CCSD $(\mathrm{T})]$ (Raghavachari et al. 1989) in conjunction with Dunning's singly augmented correlation consistent triple-zeta basis set, aug-cc-pVTZ (Dunning 1989; Peterson \& Dunning 1995) and aug-cc-pV $(\mathrm{T}+\mathrm{d}) \mathrm{Z}$ for the higher row atoms (Dunning et al. 2001). Spin-restricted (RHF) (Scheiner et al. 1987; Lee \& Rendell 1991) reference wavefunctions are used in computations involving the closed-shell anions while spin-unrestricted (UHF) (Gauss et al. 1991; Watts et al. 1992) wavefunctions are chosen for the open-shell radical computations. Dipole moments are computed at the UHF-CCSD/aug-cc-pVTZ level of theory from the UHF-CCSD(T)/aug-cc-pVTZ optimized geometry of the radical.

The computation of vertically excited states from the RHF-CCSD(T)/aug-cc-pVTZ 1 reference geometry makes use of equation of motion coupled cluster (EOM-CC) theory (Stanton \& Bartlett 1993; Monkhorst 1977; Mukherjee \& Mukherjee 1979) with increasingly diffuse basis sets constructed in an even-tempered fashion. Inclusion of this series of basis

\footnotetext{
${ }^{1}$ The aug-, n-aug-, and cc-pV $(\mathrm{X}+\mathrm{d}) \mathrm{Z}$ basis sets for the higher row atoms are simply referred to as the aug-, n-aug-, and cc-pVXZ basis sets beyond the Computational Details section for ease of discussion.
} 
sets provides evidence as to the classification of whether a state is valence or dipole-bound. A precipitous decrease in excitation energy from a standard cc-pVXZ (where $\mathrm{X}=\mathrm{D}$ or $\mathrm{T}$ ) basis set (Dunning 1989; Peterson \& Dunning 1995; Dunning et al. 2001) to t-aug-cc-pVXZ indicates the presence of a dipole-bound state. However, such is only the case if the excitation energy is below or within a computational limit (usually $0.1 \mathrm{eV}$ ) of the vertical eBE (Fortenberry \& Crawford 2011a) computed with the same level of theory and basis set for the reference geometry. These vertical eBEs are computed with the equation of motion coupled cluster theory for ionization potentials (EOMIP) (Stanton \& Gauss 1994) approach where an electron is removed from the HOMO of the anion. A valence state must also be less energetic than the vertical eBE, but its transition energy is typically much less than this limit and certainly below that of the dipole-bound state excitation energy (Fortenberry \& Crawford 2011b; Simons 2008). Additionally, the decrease in vertical excitation energy with more diffuse basis sets is much less striking for a valence state where nearly all of the necessary orbital extent is recovered with the use of the aug-cc-pVXZ basis (Skurski et al. 2000). Convergence is thus clearly achieved for computations involving the other, more highly diffuse bases.

Adiabatic computations of the eBEs and excitation energies further provide insight into the potential existence of either type of excited state since they allow for a more direct comparison to experiment (Fortenberry \& Crawford 2011ba). Adiabatic eBEs represent the energy difference between $\operatorname{CCSD}(\mathrm{T}) /$ aug-cc-pVTZ optimized geometries of the neutral and the anion (Simons 2011). Similarly, the adiabatic excitation energies are the energy difference between the CCSD/d-aug-cc-pVDZ optimized ground state and the EOM-CCSD/d-aug-cc-pVDZ optimized excited state. Also, the optimized geometries of the ground state radicals and dipole-bound excited states should be very similar, which gives a further means by which excited states can be classified. 
Core orbitals are frozen in all computations: $1 s^{2}$ for $\mathrm{B}, \mathrm{C}, \mathrm{N}$, and $\mathrm{O}$ with $1 s^{2} 2 s^{2} 2 p^{6}$ frozen for $\mathrm{Al}, \mathrm{Si}, \mathrm{P}$, and $\mathrm{S}$. All geometry optimizations are minima according to harmonic vibrational frequency analyses unless otherwise noted and discussed. The EOMIP-CC computations make use of the CFOUR (CFO 2010) quantum chemical program package, while all other computational results were obtained using the PSI3 suite of computational chemistry programs (Crawford et al. 2007).

\section{Results and Discussion}

The presence of valence excited states in silicon-containing anions from our previous studies (Fortenberry \& Crawford 2011b a) has led us to to explore if silicon's properties are unique in the retention of anionic excited states, especially valence states, or if the general properties of higher row atoms allow for behavior similar to that previously computed. The systems chosen for this study all have closed-shell ground states that are valence in nature. In order to meet this requirement, the first set of systems considered have a methylene group on one end of the structure and a single "dipole moment inducing" atom (labeled as $\mathrm{M}$ ) on the other where the two are bridged by our atom of interest, $\mathrm{X}$. These anions have the form $\mathrm{CH}_{2} \mathrm{XM}^{-}$since $\mathrm{CH}_{2} \mathrm{SiN}^{-}$appears to possess both valence and dipole-bound excited states. In the $\mathrm{CH}_{2} \mathrm{XM}^{-}$systems, $\mathrm{X}=\mathrm{N}, \mathrm{P}, \mathrm{O}$, and $\mathrm{S}$ which compare with $\mathrm{X}=\mathrm{C}$ and Si from (Fortenberry \& Crawford 2011b). M equals N when X is either O or S, but $\mathrm{M}=\mathrm{O}$ where $\mathrm{X}=\mathrm{N}$ and $\mathrm{P}$. The choice of $\mathrm{M}$ is limited to first row atoms of groups 15 or 16 due to electronegativity effects, which influence dipole moment strength, and the lack

of dipole-bound states previously computed for fluorine containing anions (Fortenberry \& Crawford 2011b).

The second set of systems studied are carbide groups paired with $\mathrm{XH}_{n}$ groups. Here the $\mathrm{X}$ atoms studied are $\mathrm{C}, \mathrm{N}, \mathrm{O}, \mathrm{Si}, \mathrm{P}$, and $\mathrm{S}$. The $n$ values are 2 when $\mathrm{X}=\mathrm{N}$ and $\mathrm{P}$, and 
$n=1$ for all other systems. This construction gives six different anions including $\mathrm{C}_{3} \mathrm{H}^{-}$and $\mathrm{CCSiH}^{-}$. These are chosen since the carbide containing $\mathrm{CCSiN}^{-}$has been shown to possess two valence excited states, (Fortenberry \& Crawford 2011a) and we are exploring how the carbide moiety can affect atoms in both rows without the inclusion of further influence from the additional $\mathrm{N}$ atom present in $\mathrm{CCSiN}^{-}$.

The third class of systems in this study is the ${ }^{1} A^{\prime} \mathrm{XH}_{3} \mathrm{YH}_{2}^{-}$systems where $\mathrm{X}=\mathrm{B}$ or $\mathrm{Al}$ and $\mathrm{Y}=\mathrm{N}$ or P. Related systems, with $\mathrm{BH}_{3} \mathrm{NH}_{3}$ being the most notable, have been the subject of much computational study, especially with regards to the nature of the $\mathrm{X}-\mathrm{Y}$

bond length, stretching frequency, and dissociation (Thorne et al. 1983: Binkley \& Thorne 1983; Marsh et al. 1992; Leboeuf et al. 1995; Reinemann et al. 2011; Sams et al. 2012). Presently, this system allows us to probe anions with group 13 elements and further explore group 15 elements. The group 15 atoms of the $\mathrm{XH}_{3} \mathrm{YH}_{2}^{-}$systems are chosen to be the $\mathrm{Y}$ atoms in the $\mathrm{YH}_{2}$ groups. This arrangement creates dipole moments in the radicals large enough to allow potentially for dipole-bound states. Additionally, some anionic and corresponding radical systems with the group 13 atoms in $\mathrm{YH}_{2}$ are not stable structures.

\subsection{Excited States of $\mathrm{CH}_{2} \mathrm{XM}^{-}$Anions}

Table 1 and Table 2 provide a summary of the data for each of the systems of interest for this work. The first system similar to $\mathrm{CH}_{2} \mathrm{CN}^{-}$and $\mathrm{CH}_{2} \mathrm{SiN}^{-}$listed in Table 1 is $\mathrm{CH}_{2} \mathrm{ON}^{-}$, which is also shown in Figure $1 \mathrm{a} \&$ Figure $2 \mathrm{a} . \mathrm{CH}_{2} \mathrm{ON}^{-}$is simply a replacement of the cyano carbon with an oxygen to create an anion similar to $\mathrm{CH}_{2} \mathrm{CN}^{-}$. Both the neutral radical and the anionic forms of $\mathrm{CH}_{2} \mathrm{ON}$ are asymmetric molecules as has been shown previously for the radical (Shapley \& Bacsky 1998). The adiabatic eBE for $\mathrm{CH}_{2} \mathrm{ON}^{-}$ cannot actually be determined here since the $C_{1}$ computations are not well-behaved in the SCF step. However, it can clearly be determined that the eBE will be lower than 0.46 
$\mathrm{eV}$, which is the adiabatic eBE from consideration of the planar $\mathrm{CH}_{2} \mathrm{ON}$ radical and the optimized asymmetric anion. This upper bound negates the existence of any stable excited states for $\mathrm{CH}_{2} \mathrm{ON}^{-}$and is much lower in energy than the vertical eBE. Even though two vertically excited states are computed to lie below the vertical eBE, only one of these dipole-bound states could exist if the adiabatic eBE was much higher (Fermi \& Teller 1947; Simons 2008).

Isomerization of $\mathrm{CH}_{2} \mathrm{ON}^{-}$to $\mathrm{CH}_{2} \mathrm{NO}^{-}$results in a species that is more energetically favorable. The computations report that $\mathrm{CH}_{2} \mathrm{NO}^{-}$is $75.0 \mathrm{kcal} / \mathrm{mol}$ more stable than the $\mathrm{CH}_{2} \mathrm{ON}^{-}$isomer. The corresponding radicals are similarly separated by around 50 $\mathrm{kcal} / \mathrm{mol}$, which is in agreement with previous computations at various levels of theory (Shapley \& Bacsky 1998, 1999). These two anions have comparable dipole moments of $\sim 2.3 \mathrm{D}$ as shown in Table 1. $\mathrm{CH}_{2} \mathrm{NO}^{-}$and its excited state properties have been previously examined by Fortenberry \& Crawford (2011b), but they are relevant for this discussion. The $1.55 \mathrm{eV}$ adiabatic excitation energy to the lowest excited state $\left(2^{1} A^{\prime}\right)$ is more than 0.1 $\mathrm{eV}$ higher than the $1.42 \mathrm{eV}$ adiabatic $\mathrm{eBE}$, which indicates that this state does not exist. However, vertical excitation energies from the RHF-CCSD(T)/aug-cc-pVTZ optimized geometry reported in Table 2 show a clear pattern of energy decrease with the inclusion of more diffuse functions indicative of a highly diffuse dipole-bound state. Interestingly, the vertical CCSD/t-aug-cc-pVTZ eBE computed via EOMIP is much higher than the vertical EOM-CCSD/t-aug-cc-pVTZ $2{ }^{1} A^{\prime}$ state energy. However, the adiabatic results better model physical behavior and this leads to the conclusion that, again, $\mathrm{CH}_{2} \mathrm{NO}^{-}$probably does not possess any bound singlet excited states.

Phosphorus substitution for the nitrogen atom in $\mathrm{CH}_{2} \mathrm{NO}^{-}$to give $\mathrm{CH}_{2} \mathrm{PO}^{-}$and sulfur substitution of the oxygen atom in $\mathrm{CH}_{2} \mathrm{SN}^{-}$both appear to give dipole-bound states. $\mathrm{CH}_{2} \mathrm{PO}$ radical's dipole moment of $2.477 \mathrm{D}$ is well above Fermi and Teller's Fermi \& 
Teller 1947) theoretical 1.625 D necessary dipole moment for a dipole-bound state in the corresponding anion and right at Gutsev and Adamowicz's (Gutsev \& Adamowicz 1995) more practical 2.5 D limit. The 2.477 D dipole moment for $\mathrm{CH}_{2} \mathrm{PO}$ is higher than either of the previous first row analogues, indicating that presence of the second row atom has some effect on the system.

The adiabatic transition energy to the first excited state of $\mathrm{CH}_{2} \mathrm{PO}^{-}, 1^{1} A^{\prime \prime}$, is computed to be $2.89 \mathrm{eV}$, while the eBE is $2.82 \mathrm{eV}$. This is within the $0.1 \mathrm{eV}$ limit of computational accuracy. Vertically, the eBE is $2.79 \mathrm{eV}$, and the vertical excited state energy for the t-aug-cc-pVDZ basis set is the same. Coupling these factors with a steep decline in the vertical excitation energy for increasingly more diffuse basis sets shown in Table 2 gives classic behavior of a dipole-bound excited state. However, the excitation into a highly diffuse $s$-type (totally symmetric) orbital necessitates that the term for the dipole-bound excited state must be directly related to the term of the radical, ${ }^{2} A^{\prime}$ in this case. There is a second excited state of $\mathrm{CH}_{2} \mathrm{PO}^{-}, 2{ }^{1} A^{\prime}$, that has an adiabatic excitation energy $(3.08 \mathrm{eV})$ much higher than 2.82 adiabatic eBE. Its t-aug-cc-pVDZ vertical excitation energy of 2.81 $\mathrm{eV}$ is only $0.02 \mathrm{eV}$ higher than the vertical eBE. Another key hallmark of a dipole bound state is that due to the diffuseness of the orbital in which the bound electron is held, the excited anion will take on not only the similar term but also the geometry of the radical whose dipole moment is binding the electron. Figure $2 \mathrm{~d}$ shows that the $2{ }^{1} A^{\prime} \mathrm{CH}_{2} \mathrm{PO}^{-}$ geometry is very much like the Figure $1 \mathrm{~d} \mathrm{CH}_{2} \mathrm{PO}$ geometry. Additionally, only one dipole bound state can exist for any given anion (Fermi \& Teller 1947; Simons 2008). Hence, the 2 ${ }^{1} A^{\prime}$ state is actually the dipole-bound state, but the adiabatic results for this dipole-bound excited state do not suggest that it will be stable since it is more than $0.1 \mathrm{eV}$ higher than the eBE.

The $1^{1} A^{\prime \prime}$ state of $\mathrm{CH}_{2} \mathrm{SN}^{-}$behaves somewhat differently than the analogous $3{ }^{1} \mathrm{~A}$ 
state of $\mathrm{CH}_{2} \mathrm{ON}^{-}$. There is relatively little change in the vertical excitation energy (0.72 $\mathrm{eV}$ ) from cc-pVDZ to t-aug-cc-pVDZ for the $\mathrm{CH}_{2} \mathrm{SN}^{-} 1^{1} A^{\prime \prime}$ state, and the vertical eBE at $2.24 \mathrm{eV}$ is higher than the t-aug-cc-pVDZ excitation energy at $2.04 \mathrm{eV}$. However, the change from d- to t-aug-cc-pVDZ excitation energy is fairly substantial at $0.39 \mathrm{eV}$. This is over half of the total decrease in excitation energy across the range of diffuse basis sets indicating that there is a mixture of valence and dipole-bound character. Even so, there is not enough pure valence character in the excitation in order for this state to be predominantly valence in nature. Similar vertical CC3 excited state computations also do not give any further evidence to show that the $1^{1} A^{\prime \prime}$ state is a valence state. Additionally, the adiabatic excitation energy for this state is more than $0.1 \mathrm{eV}$ higher than the adiabatic eBE. As a result, we must conclude that the $1^{1} A^{\prime \prime}$ state of $\mathrm{CH}_{2} \mathrm{SN}^{-}$is not accessible. Differently, the lower $2^{1} A^{\prime}$ state is the dipole-bound state since the adiabatic eBE in Table 1 is $0.03 \mathrm{eV}$ above the excitation energy, the basis set convergence in Table 2 is consistent with dipole-bound states, and the geometry of the radical in Table 1 is comparable to that of the optimized $2{ }^{1} A^{\prime}$ state.

For $\mathrm{CH}_{2} \mathrm{SN}$, both the radical and the anion are planar while its first row analogue, $\mathrm{CH}_{2} \mathrm{ON}$, is asymmetric in both electronic occupations. The "reluctance to hybridize" (Kutzelnigg 1984; Driess \& Grützmacher 1996) in the sulfur atom allows $\mathrm{CH}_{2} \mathrm{SN}^{-}$to remain planar, whereas the $\mathrm{MOs}$ in $\mathrm{CH}_{2} \mathrm{ON}^{-}$force the hydrogens in the methylene group to pyramidalize. This same behavior is present in $\mathrm{CH}_{2} \mathrm{CN}^{-}$. Hence, the geometrical differences and the subsequent subtle changes to the orbitals for the inclusion of larger atoms from the second row alone do not bring about valence states. Otherwise, the sulfur-containing anion, $\mathrm{CH}_{2} \mathrm{SN}^{-}$, would have at least one valence state. While it is fascinating that these anions containing higher row atoms possess dipole-bound excited states and the analogous first row anions do not, it is the search for valence states that is driving this study. Even though the $\mathrm{CH}_{2} \mathrm{XM}^{-}$anions are as close as possible to the structure of $\mathrm{CH}_{2} \mathrm{SiN}^{-}$, these anions with 
second row elements do not give similar valence excitations. However, the inclusion of a single second row atom systematically increases the eBEs as compared to the first row only anions. This increase appears to open up the possibility for excited states to be present in the spectra of anions containing second row atoms, but it does not guarantee the existence of stable valence states.

\section{2. $\quad$ Excited States of $\mathrm{CCXH}_{n}^{-}$Anions}

Molecules containing a carbide group have gained recent interest in relation to the diffuse interstellar bands, (Linnartz et al. 2010; Maier et al. 2011) and this moiety is present in $\mathrm{CCSiN}^{-}$, which has been shown to possess two valence states (Fortenberry \& Crawford 2011a). As a result, simple anions of the $\mathrm{CCXH}_{n}^{-}$family where $\mathrm{X}=\mathrm{C}, \mathrm{N}$, and $\mathrm{O}$, as well as their second row analogues Si, S, and P, are examined here. An interesting feature of the entire $\mathrm{CCXH}_{n}^{-}$family of anions is that the corresponding radicals all have very large dipole moments from $3.409 \mathrm{D}$ for $\mathrm{C}_{3} \mathrm{H}$ to nearly $6 \mathrm{D}$ for $C_{2 v} \mathrm{CCNH}_{2}$. This behavior does not vary for the inclusion of the first or second row atoms; the carbide moiety is responsible for the large dipole moments. Previous computations of the dipole moment for $\mathrm{CCOH}$ are consistent, (Yamaguchi et al. 1998; Fortenberry \& Crawford 2011b) and the 3.409 D dipole moment of $\mathrm{C}_{3} \mathrm{H}$ is also in line with previous CASSCF computations of its dipole moment, 3.163 D, by Takahashi and Yamashita (Takahashi \& Yamashita 1996).

The $\mathrm{C}_{3} \mathrm{H}^{-}$system has received much attention over the past two decades (Takahashi \& Yamashita 1996; Ochsenfeld et al. 1997; Pachkov et al. 2001; Pino et al. 2004; Sheehan et al. 2008) mainly examining the anion to neutral (triplet to doublet) photochemistry. Even though it has been reported that the cyclic singlet is the most stable isomer of $\mathrm{C}_{3} \mathrm{H}^{-}$, (Sheehan et al. 2008) consistency for the scope of this study and how $\mathrm{C}_{3} \mathrm{H}$ relates to the other anions from groups 15 and 16 in these $\mathrm{CCXH}_{n}^{-}$model systems mandates exploration 
of the excited state properties of the $C_{s}$ pseudo-linear ${ }^{1} A^{\prime} \mathrm{C}_{3} \mathrm{H}^{-}$and the silicon analogue, $\mathrm{CCSiH}^{-}$. $\mathrm{CCSD}(\mathrm{T}) /$ aug-cc-pVTZ computations put the ${ }^{1} A_{1} c-\mathrm{C}_{3} \mathrm{H}^{-}$isomer only 6.6 $\mathrm{kcal} / \mathrm{mol}$ lower in energy than the ${ }^{1} A^{\prime} \mathrm{C}_{3} \mathrm{H}^{-}$isomer. The pseudo-linear singlet isomer is 6.9 $\mathrm{kcal} / \mathrm{mol}$ lower in energy than ${ }^{3} A^{\prime} \mathrm{C}_{3} \mathrm{H}^{-}$.

Fascinatingly, pseudo-linear $\mathrm{C}_{3} \mathrm{H}^{-}$appears to possess a valence state. Table 1 shows that the adiabatic excitation energy of the $1^{1} A^{\prime \prime} \leftarrow 1^{1} A^{\prime}$ transition at $0.93 \mathrm{eV}$ is much less than the $1.83 \mathrm{eV}$ adiabatic eBE. The vertical excitation energies for the increasingly diffuse basis sets given in Table 2 decrease from $1.21 \mathrm{eV}$ for cc-pVDZ merely to $1.15 \mathrm{eV}$ for aug-cc-pVDZ and to $1.14 \mathrm{eV}$ for the converged excitation energy for d- and t-aug-cc-pVDZ. The converged vertical excitation energy is well below the 2.34 vertical eBE. Finally, the excited state geometry given in Figure $2 \mathrm{k}$ is markedly different from the radical geometry in Figure $1 \mathrm{k}$, especially for the $\mathrm{H}-\mathrm{C}_{3}-\mathrm{C}_{2}$ bond angle. Differently, the vertical excitation energy of the $2^{1} A^{\prime} \leftarrow 1^{1} A^{\prime}$ transition at $2.37 \mathrm{eV}$ for t-aug-cc-pVDZ is just above (but within computational accuracy of) the vertical eBE. However, the adiabatic computations put this state at $2.05 \mathrm{eV}, 0.22 \mathrm{eV}$ above the adiabatic eBE. Our analysis strongly indicates that a valence state is present in this anion. It may yet possess a dipole-bound state in addition to its valence excited state, but our computations do not strongly support this interpretation.

The silicon analogue, $\mathrm{CCSiH}^{-}$, exhibits similar behavior. The $2.06 \mathrm{eV} 1^{1} A^{\prime \prime} \leftarrow 1^{1} A^{\prime}$ excitation energy is also well under the $3.11 \mathrm{eV}$ adiabatic eBE. Table 2 also confirms that the $1^{1} A^{\prime \prime}$ state is valence in nature since the more diffuse basis sets lower the vertical excitation energy for this state by only $0.04 \mathrm{eV}$. The vertical eBE at $3.27 \mathrm{eV}$ is, again, well above the vertical excitation energy. Differently, the $2^{1} A^{\prime}$ state appears to be the dipole-bound state of $\mathrm{CCSiH}^{-}$. Like the analogous $2{ }^{1} A^{\prime}$ state of $\mathrm{C}_{3} \mathrm{H}^{-}$, this state is also more than $0.1 \mathrm{eV}$ above the eBE adiabatically, but it is only $0.12 \mathrm{eV}$ higher than the eBE 
here. The EOM-CCSD/t-aug-cc-pVDZ vertical excitation energy of $3.26 \mathrm{eV}$ is actually 0.01 $\mathrm{eV}$ less than the vertical eBE. Hence, the dipole-bound state is more likely to be present in the spectrum of $\mathrm{CCSiH}^{-}$than that of $\mathrm{C}_{3} \mathrm{H}^{-}$, but the presence of dipole-bound states for these systems cannot be confirmed. Regardless, both $\mathrm{C}_{3} \mathrm{H}^{-}$and $\mathrm{CCSiH}^{-}$show clear indications of possessing $1^{1} A^{\prime \prime}$ valence states, the first time our methodology is reporting a valence state for a small anion without silicon.

The valence state for $\mathrm{C}_{3} \mathrm{H}^{-}$is probably the result of a more favorable orbital arrangement arising from the presence of the carbene. This allows the valence $a^{\prime \prime}$ virtual orbital involved in the excitation to be more easily accessed photochemically. Figure 1 1 k \& Figure 11. show that the ground state structures of $\mathrm{C}_{3} \mathrm{H}^{-}$and $\mathrm{CCSiH}^{-}$are both substantially bent at the $\mathrm{C}-\mathrm{X}-\mathrm{H}(\mathrm{X}=\mathrm{C}, \mathrm{Si})$ bond angle. The $\mathrm{C}_{3} \mathrm{H}^{-}$ground state $\mathrm{C}-\mathrm{C}-\mathrm{H}$ bond angle is $109.1^{\circ}$, while this same angle for the radical in Figure $1 \mathrm{k}$ is $162.7^{\circ}$. The ground state anionic $\mathrm{C}-\mathrm{Si}-\mathrm{H}$ bond angle is much closer to perpendicular at $99.8^{\circ}$ as shown in Figure 1 . The similar $\mathrm{C}-\mathrm{C}-\mathrm{H}$ bend in $\mathrm{C}_{3} \mathrm{H}^{-}$allows its orbitals to behave more like those in $\mathrm{CCSiH}^{-}$than in previous first-row-only anions studied. One interpretation of this result is that the central carbene carbon in the $\mathrm{C}-\mathrm{C}-\mathrm{H}$ bond angle in $\mathrm{C}_{3} \mathrm{H}^{-}$has less "hybridized" character since the $\mathrm{C}-\mathrm{C}-\mathrm{H}$ bond angle is noticeably less than the desired $120^{\circ}$ typically associated with an $\mathrm{sp}^{2}$ carbon. Such a result is, again, a well-known property of singlet carbenes (Bourissou et al. 2000). Consequently, the carbene carbon is behaving more like silicon, which is much less likely to hybridize (Kutzelnigg 1984; Driess \& Grützmacher 1996) as is evidenced by its even smaller $\mathrm{C}-\mathrm{Si}-\mathrm{H}$ bond angle in $\mathrm{CCSiH}^{-}$(99.8 ${ }^{\circ}$ in the ground state) consistent with the $92.1^{\circ} \mathrm{H}-\mathrm{Si}-\mathrm{H}$ bond angle in singlet $\mathrm{SiH}_{2}$ (Driess \& Grützmacher 1996; Dubois 1968). Further interpretation of the presence of valence states and the $\mathrm{C}-\mathrm{X}-\mathrm{H}$ bond angles of less than $120^{\circ}$ in both $\mathrm{C}_{3} \mathrm{H}^{-}$and $\mathrm{CCSiH}^{-}$is that the the amount of recoupled pair bonding in $\mathrm{C}_{3} \mathrm{H}^{-}$is much less than that present in typical carbon systems and is more like that from higher row, early $p$-block atoms such as silicon (Woon \& Dunning 2011; Shaik et al. 2012). 
The presence of the $\mathrm{CCOH}^{-}$dipole-bound $1^{1} A^{\prime \prime}$ excited state is unclear (Fortenberry \& Crawford 2011b). However, the existence of the dipole-bound $1^{1} A^{\prime \prime}$ excited state of the sulfur analogue analyzed in this study, $\mathrm{CCSH}^{-}$, is more promising. This corresponding radical was first analyzed photochemically to compare its chemistry to $\mathrm{CCOH}$ and $\mathrm{HCCO}$ (Venkatasubramanian \& Krishnamachari 1991). CCSH shares similarities with CCOH in that the $4.492 \mathrm{D}$ dipole moment is similar to the $4.401 \mathrm{D}$ dipole moment of $\mathrm{CCOH}$. The adiabatic excitation energy for the $1^{1} A^{\prime \prime}$ state of $\mathrm{CCSH}^{-}$is approximated to be $2.82 \mathrm{eV}$ since the geometry optimizations could not converge the root mean squared force to better than $10^{-3} E_{h} / a_{0}$. However, this approximate excitation energy is still $0.04 \mathrm{eV}$ lower than the adiabatic eBE. Additionally, the trend of vertical excitations places this excitation beneath the vertical eBE, giving strong evidence that this state is present in the electronic spectrum of $\mathrm{CCSH}^{-}$. Combining these factors with the similarities in the optimized geometry of the radical and the approximate geometry of the anion, especially for the $\mathrm{H}-\mathrm{S}-\mathrm{C}_{2}$ bond angle from Figure $1 \mathrm{~m} \&$ Figure $2 \mathrm{~m}$, the $1^{1} A^{\prime \prime}$ state of $\mathrm{CCSH}^{-}$is a dipole-bound state. However, no evidence is present for a valence state of $\mathrm{CCSH}^{-}$.

It was hoped that the large $5.903 \mathrm{D}$ dipole moment of the stable $(\mathrm{TaO} 2005) \mathrm{CCNH}_{2}$ radical would increase the anionic eBE enough so that a valence state could exist, but our computations show that no valence state is present for this anion. A dipole-bound state does appear to be present for $\mathrm{CCNH}_{2}^{-}$, an isomer of $\mathrm{CH}_{2} \mathrm{CN}^{-}$, which is the anion hypothesized to be a DIB carrier (Cordiner \& Sarre 2007; Fortenberry et al. 2013). The adiabatic excitation energy of the $1^{1} B_{1}$ state $\left(2{ }^{1} A^{\prime}\right.$ in the vertical computations) of $\mathrm{CCNH}_{2}^{-}$is $2.00 \mathrm{eV}$, while the adiabatic eBE is nearly coincident at $1.97 \mathrm{eV}$, which is within the computational limit for this state to exist. The vertical computations fully place the eBE higher than the excitation energy. Additionally, the optimized bond angles and bond lengths of the anion excited state and those of the radical given in Figure 1e \& Figure 2 e show a strong correspondence, and the excited state is of $C_{2 v}$ symmetry like that of the 
radical. Hence, the first excited state of $\mathrm{CCNH}_{2}^{-}$is the dipole-bound state. No valence states exist.

The second row analogue, $\mathrm{CCPH}_{2}^{-}$, exhibits similar dipole-bound behavior in its 2 ${ }^{1} A^{\prime}$ state. The dipole moment of the radical is smaller than the $\mathrm{N}$ analogue, but it is still quite large at $4.759 \mathrm{D}$. The $2^{1} A^{\prime}$ state excites at $3.16 \mathrm{eV}$ from adiabatic computations. The adiabatic eBE is slightly more than this at $3.21 \mathrm{eV}$, which is strong evidence that this state is bound upon excitation. Additionally, the energy progression with increased diffuse character of the basis set for the vertical excitation energy of this $\mathrm{CCPH}_{2}^{-}$state clearly shows that it is indeed dipole-bound in nature and also underneath the vertical eBE. Comparison of the geometries in Figure 1 f \& Figure $2 f$ gives further evidence for the 2 ${ }^{1} A^{\prime}$ state to be dipole-bound. Like its first row analogue, $\mathrm{CCPH}_{2}^{-}$possesses one state that exhibits dipole-bound character, but no valence states appear to be present even though the adiabatic eBE for $\mathrm{CCPH}_{2}^{-}$is $1.24 \mathrm{eV}$ greater than that of $\mathrm{CCNH}_{2}^{-}$.

\section{3. $\quad$ Excited States of $\mathrm{XH}_{3} \mathrm{YH}_{2}^{-}$Anions}

The $\mathrm{XH}_{3} \mathrm{YH}_{2}$ systems are all depicted in Figure 1 and Figure 2 in items g-j. These systems are based on the dative bonding molecule ammonia borane, $\mathrm{BH}_{3} \mathrm{NH}_{3}$, but the removal of a hydrogen from the nitrogen changes the bonding chemistry. For instance, experiment and theory both agree that the $\mathrm{B}-\mathrm{N}$ bond length in standard ammonia borane is $1.657 \AA$ (Thorne et al. 1983 ; Sams et al. 2012). The lone pair on the ammonia molecule fills the empty out-of-plane $p$ orbital in the borane. Hence, the bonding environment is not truly covalent but dative as evidenced by the long $\mathrm{B}-\mathrm{N}$ bond length. However, our systems have shorter $\mathrm{B}-\mathrm{N}$ bond lengths than other dative structures. As shown in Figure $1 \mathrm{p}$, the $1.448 \AA \mathrm{A}-\mathrm{N}$ bond length in $\mathrm{BH}_{3} \mathrm{NH}_{2}$ is much less than the standard ammonia borane dative bond. Even though the anion has a longer B-N bond than the radical at 
$1.584 \AA$, this bond is still much shorter than dative bonds in similar systems (Reinemann et al. 2011).

The molecules examined for this study appear to have a combination of dative and covalent bonding due to the presence of bonds longer than typical covalent bonds but not as long as dative bonds. For instance, $\mathrm{BH}_{3} \mathrm{NH}_{2}^{-}$can be thought of as the aminoborane anion, a $C_{s}$ molecule with the plane of symmetry contained in the $\mathrm{B}-\mathrm{N}$ bond bisecting the $\mathrm{H}-\mathrm{N}-\mathrm{H}$ bond angle. The borane still has its empty $p$ orbital which is filled not by the nitrogen's lone pair but by another pair of electrons from the nitrogen giving a standard covalent interaction while nitrogen retains its lone pair. Hence, the bonding is mixed from the covalency of the amino group and the dative interaction originating from the borane. The ground state of the $\mathrm{BH}_{3} \mathrm{NH}_{2}$ radical actually has a different geometrical conformation than the anion. Its geometry is rotated so that the plane of symmetry in this $C_{s}$ radical contains both the $\mathrm{B}-\mathrm{N}$ bond and the $\mathrm{H}-\mathrm{N}-\mathrm{H}$ bond angle.

The aminoborane anion, $\mathrm{BH}_{3} \mathrm{NH}_{2}^{-}$, gives some evidence for the possession of a dipole-bound excited state. The radical has a dipole moment (2.524 D) large enough for one to exist, but the $2.28 \mathrm{eV}$ adiabatic eBE given in Table 1 is much lower than the adiabatic excitation energy to the $2{ }^{1} A^{\prime}$ state at $2.53 \mathrm{eV}$. Differently, the vertical eBE of $2.88 \mathrm{eV}$ given in Table 2 is coincident with the converged vertical excitation energy for this state. Even though the energy difference between the eBE and excitation energy adiabatically appears to be too great to support a dipole-bound state, the vertical computations show that if this excited state does exist it is probably dipole-bound. The $2{ }^{1} A^{\prime}$ state of $\mathrm{BH}_{3} \mathrm{NH}_{2}^{-}$ has a geometry similar in many respects to that of the radical from the the bottom values of Figure $1 \mathrm{~g} \&$ Figure $2 \mathrm{~g}$, but the $\mathrm{H}-\mathrm{B}-\mathrm{H}$ bond angle discrepancies highlight that these are geometrically different enough for the $2^{1} A^{\prime}$ state not to be purely dipole-bound. There is mixing in the character of the excited state wavefunction, and it is great enough to 
stabilize this state before it assumes an optimized geometry similar to that of the radical. Regardless, our adiabatic energy difference in the eBE and excitation energy of $0.25 \mathrm{eV}$ is probably too great for this excited state to exist.

Not surprisingly, both the $\mathrm{BH}_{3} \mathrm{PH}_{2}$ radical and anion have longer central bonds than the analogous aminoborane compounds due to the larger valence orbitals present in the phosphorus atom. Figure $1 \mathrm{~h}$ shows this increase to be on the order of $0.4 \AA$ for the anion and $0.5 \AA$ for the radical. Also, the $\mathrm{B}-\mathrm{P}-\mathrm{H}$ bond angles are smaller in the $\mathrm{BH}_{3} \mathrm{PH}_{2}$ systems than the $\mathrm{B}-\mathrm{N}-\mathrm{H}$ bond angles in the $\mathrm{BH}_{3} \mathrm{NH}_{2}$ systems. This is, again, typical of second row atoms (Driess \& Grützmacher 1996). Additionally, the $C_{s} \mathrm{BH}_{3} \mathrm{PH}_{2}$ radical has its plane of symmetry bisecting the $\mathrm{H}-\mathrm{P}-\mathrm{H}$ bond angle. This is consistent with the corresponding anion but different from the $\mathrm{BH}_{3} \mathrm{NH}_{2}$ radical. The dipole moment of $\mathrm{BH}_{3} \mathrm{PH}_{2}$ is slightly larger than its first row analogue at 2.889 D. This makes it large enough for the corresponding anion to possess a dipole-bound state, which it appears to have. Table 1 shows the adiabatic excitation to the $2{ }^{1} A^{\prime}$ state of $\mathrm{BH}_{3} \mathrm{PH}_{2}^{-}$to be $2.78 \mathrm{eV}$, while the adiabatic eBE is within our $0.1 \mathrm{eV}$ cutoff at $2.74 \mathrm{eV}$. The adiabatic eBE is also nearly 0.5 $\mathrm{eV}$ greater than the $\mathrm{BH}_{3} \mathrm{NH}_{2}^{-}$adiabatic eBE. The vertical excitation energy converges to the same value as the vertical eBE, $3.26 \mathrm{eV}$, for the double-zeta basis sets. Hence, the lone stable excited state, the $2{ }^{1} A^{\prime}$ state, of $\mathrm{BH}_{3} \mathrm{PH}_{2}^{-}$appears to dipole-bound.

The insertion of aluminum into the $\mathrm{XH}_{3} \mathrm{YH}_{2}^{-}$systems brings about some interesting chemistry. From Figure 1 , the $\mathrm{Al}-\mathrm{N}$ bond $(1.887 \AA)$ in $\mathrm{AlH}_{3} \mathrm{NH}_{2}^{-}$is longer than the original $\mathrm{B}-\mathrm{N}$ bond $(1.584 \AA)$, but it is not quite as long the $\mathrm{B}-\mathrm{P}$ bond in $\mathrm{BH}_{3} \mathrm{PH}_{2}^{-}(2.013$ $\AA$ ). Additionally, the $\mathrm{Al}-\mathrm{N}$ bonds in both the $\mathrm{AlH}_{3} \mathrm{NH}_{2}$ radical and anion are shorter than the previously computed $\mathrm{Al}-\mathrm{N}$ bond lengths in $\mathrm{AlH}_{3} \mathrm{NH}_{3}$, which are more than 2.0 $\AA$, irrespective of the level of theory employed (Marsh et al. 1992; Leboeuf et al. 1995). This is similar to the mixed covalent/dative bonding in the boranes above. However, the 
$\mathrm{N}-\mathrm{Al}-\mathrm{H}$ bond angle contained within the plane of symmetry in these $C_{s}$ molecules is beyond perpendicular for both the $\mathrm{AlH}_{3} \mathrm{NH}_{2}\left(68.2^{\circ}\right)$ and $\mathrm{AlH}_{3} \mathrm{PH}_{2}\left(69.7^{\circ}\right)$ radicals. The anions revert back to more typical bond angles (Marsh et al. 1992, Leboeuf et al. 1995) once the out of plane $p$ orbital in the $\mathrm{N}$ or $\mathrm{P}$ atom is filled to give the standard lone pair.

Both alane species, $\mathrm{AlH}_{3} \mathrm{NH}_{2}^{-}$and $\mathrm{AlH}_{3} \mathrm{PH}_{2}^{-}$, have two excited states adiabatically either below or within $0.1 \mathrm{eV}$ of their respective eBEs as given in Table 1. The inclusion of aluminum significantly increases the eBEs as compared to the aminoborane or phosphinoborane anions, especially when phosphorus is also included. The corresponding radical to $\mathrm{AlH}_{3} \mathrm{NH}_{2}^{-}$has the stronger dipole moment at $2.579 \mathrm{D}$ whereas the dipole moment of $\mathrm{AlH}_{3} \mathrm{PH}_{2}$ is somewhat below Gutsev and Adamowicz's (Gutsev \& Adamowicz 1995) $2.5 \mathrm{D}$ limit at $2.167 \mathrm{D}$. This ensures that neither dipole moment is strong enough to bind a second dipole-bound state and maybe not a first (Fermi \& Teller 1947; Gutsev \& Adamowicz 1995; Simons 2008). The only way that both states in each alane anion may be retained is if one is valence. Table 2 gives the vertical excitation energies and eBEs for both the $2{ }^{1} A^{\prime}$ and $1{ }^{1} A^{\prime \prime}$ states of both alanes. In each of the two cases, the higher $1^{1} A^{\prime \prime}$ state excitation energy $\left(3.85 \mathrm{eV}\right.$ and $3.86 \mathrm{eV}$, respective of $\mathrm{AlH}_{3} \mathrm{NH}_{2}^{-}$and $\mathrm{AlH}_{3} \mathrm{PH}_{2}^{-}$) is in the range of what we expect for a classic dipole-bound state since the eBEs are $3.80 \mathrm{eV}$ and $3.85 \mathrm{eV}$, respectively. The basis set convergence confirms the dipole-bound character for both states of both anions. However, if the lower energy excited states are dipole-bound, only the lower energy states can exist since only one dipole-bound state is allowed for these dipole moment magnitudes (Fermi \& Teller 1947).

The classification of the lower $2{ }^{1} A^{\prime}$ states for each alane anion is a bit more nebulous. Due to the orbitals involved in the excitation with the highly diffuse basis sets, no vertical excitation energies for the cc-pVDZ or cc-pVTZ basis sets could be conclusively linked to comparable excitations utilizing the more diffuse basis sets. This is marked in Table 2. The 
lack of correlation in vertical excitation energies does not indicate valence excitation since all previous valence excitations characterized with this methodology have had little change in the excitation energy from the cc-pVDZ vertical excitation energy out to those computed with more diffuse basis sets. Additionally, the vertical excitation energy convergence for the double zeta basis sets from the aug-cc-pVDZ to the t-aug-cc-pVDZ level has previously been less than $0.1 \mathrm{eV}$ for valence states. The change in vertical excitation energies due to basis set augmentation for the $2{ }^{1} A^{\prime}$ state of $\mathrm{AlH}_{3} \mathrm{NH}_{2}^{-}$is $0.30 \mathrm{eV}$ and $0.42 \mathrm{eV}$ for the 2 ${ }^{1} A^{\prime}$ state of $\mathrm{AlH}_{3} \mathrm{PH}_{2}^{-}$. However, the change from d-aug-cc-pVDZ to t-aug-cc-pVDZ in the aminoalane anion is only $0.01 \mathrm{eV}$ and $0.04 \mathrm{eV}$ in the phosphinoalane. To further complicate the interpretation, the optimized geometries of the $2{ }^{1} A^{\prime}$ states of both anions (given in Figures 2 \& j) are not as similar to the optimized geometries of the $1{ }^{2} A^{\prime}$ states of the radicals as one would expect for dipole-bound states. For instance, the $\mathrm{Al}-\mathrm{Y}(\mathrm{Y}=\mathrm{N} \& \mathrm{P})$ bond lengths are on the order of $0.1 \AA$ longer in the anion excited states than they are in the corresponding radicals. The $\mathrm{Al}-\mathrm{Y}-\mathrm{H}$ bond angles are larger in the excited $2{ }^{1} A^{\prime}$ states of the anion than they are in the radical: $121.8^{\circ}$ in the $\mathrm{AlH}_{3} \mathrm{NH}_{2}$ radical as opposed to $125.7^{\circ}$ for the $2{ }^{1} A^{\prime}$ state of the anion and $108.0^{\circ}$ for the $\mathrm{AlH}_{3} \mathrm{PH}_{2}$ radical while the excited state of the anion has this bond angle at $126.6^{\circ}$. Similar to $\mathrm{BH}_{3} \mathrm{NH}_{2}$, these two closely related cases appear to have mixed valence/dipole-bound character, the most of which for any anionic excited states examined so far with this methodology. It is unclear if the valence character mixed into these excited states is large enough to allow the higher, clearly dipole-bound states to exist above them. Regardless, the presence of at least one excited state, the $2{ }^{1} A^{\prime}$, in the electronic spectra is possible for both $\mathrm{AlH}_{3} \mathrm{NH}_{2}^{-}$and $\mathrm{AlH}_{3} \mathrm{PH}_{2}^{-}$. 


\section{Conclusions}

In the further examination of singlet excited states of small, closed-shell molecular anions, specifically those that may possess valence excited states, we have examined new species containing the second row atoms Al, Si, S, and P. Of the twelve new anions examined here with further inclusion of $\mathrm{CH}_{2} \mathrm{NO}^{-}$and $\mathrm{CCOH}^{-}$previously studied by Fortenberry \& Crawford (2011b), nine exhibit definite bound excited state character: $\mathrm{CH}_{2} \mathrm{SN}^{-}, \mathrm{C}_{3} \mathrm{H}^{-}$, $\mathrm{CCSiH}^{-}, \mathrm{CCSH}^{-}, \mathrm{CCNH}_{2}^{-}, \mathrm{CCPH}_{2}^{-}, \mathrm{BH}_{3} \mathrm{PH}_{2}^{-}, \mathrm{AlH}_{3} \mathrm{NH}_{2}^{-}$, and $\mathrm{AlH}_{3} \mathrm{PH}_{2}^{-}$. Only two of these, $\mathrm{C}_{3} \mathrm{H}^{-}$and $\mathrm{CCNH}_{2}^{-}$, do not contain second row atoms. Adiabatic computations indicate that $\mathrm{CH}_{2} \mathrm{ON}^{-}, \mathrm{CH}_{2} \mathrm{NO}^{-}, \mathrm{CCOH}^{-}$, and $\mathrm{BH}_{3} \mathrm{NH}_{2}^{-}$do not possess excited states, dipole-bound or otherwise, and $\mathrm{CH}_{2} \mathrm{PO}^{-}$likely does not either.

The only silicon system examined in this study, $\mathrm{CCSiH}^{-}$, possesses two excited states: one valence and one dipole-bound. Interestingly, the carbon analogue, $\mathrm{C}_{3} \mathrm{H}^{-}$, also exhibits both a single valence excited state and a dipole-bound excited state. This is possibly the

result of similar orbital arrangements present in both systems that was not present in those first and second row analogues previously studied. In this regard, silicon does not appear unique in its ability to foster valence singlet excited states in anions. Even so, when varying the atoms at all non-hydrogen and non-dipole-inducing positions, only the inclusion of group 14 atoms has been shown to contribute to stable valence excitations for closed-shell anions. This could also be true for inclusion of a directed group 15 and 16 atom since the presence of these second row atoms increases the eBEs noticeably as compared to their first row analogues. However, the properties of anions with group 15 and 16 atoms do not appear as favorable for the existence of valence excited states of closed-shell anions based on the systems analyzed both here and previously (Fortenberry \& Crawford 2011b a).

Mixing of valence and dipole-bound character in the excited state wavefunctions can be more substantial than originally thought. This is present in some of the carbide anions, but 
the aminoborane anion and its analogues, especially the alanes, have substantial mixing of valence and dipole-bound excited state character in their first excited states. The vertical excitation energies for $\mathrm{AlH}_{3} \mathrm{NH}_{2}^{-}$and $\mathrm{AlH}_{3} \mathrm{PH}_{2}^{-}$, for example, shift noticeably for more diffuse basis sets unlike typical valence excitations but not as much as the shifts observed for established dipole-bound anions. The mixing is also showcased in the lack of correspondence between the optimized radical and excited $2{ }^{1} A^{\prime}$ state geometries. It is unclear if the amount of mixing in these first excited states gives enough valence character for the second state to play the role of the "threshold resonance," but the order of magnitude variance in the oscillator strengths (Table 2 ) between the lower and stronger $2{ }^{1} A^{\prime}$ states and the higher and less intense $1^{1} A^{\prime \prime}$ states of each alane anion would make this experimentally measurable.

The presence of second row atoms in the types of closed-shell anions examined thus far increases the likelihood of dipole-bound excited states since the eBE and dipole moments are both increased with the larger atoms. Combining these facts with the increased prevalence of mixing for valence and dipole-bound character in the excited state wavefunction indicates that the larger atoms create environments more favorable for excitation of electrons in closed-shell anions, but the anions built around group 14 atoms, especially silicon, are the most favorable for anion excitation.

Finally, direct attribution of known DIBs to computed anionic excitations is impractical for the present level of computational accuracy. However, the accuracy range combined with the density of the DIBs (with a band present every nm or so between $400 \mathrm{~nm}$ and $880 \mathrm{~nm}$ ) gives many options for correlation between the computed transitions of our set of anions and the various DIBs (Joblin et al. 1990; Jenniskens \& Desert 1994; Jenniskins \& Désert 1995). In fact, one of the longest wavelength DIBs at $1317.5 \mathrm{~nm}$ (Joblin et al. 1990) is in the proper range to be related potentially to the $1328 \mathrm{~nm}$ dipole-bound $1^{1} A^{\prime \prime} \leftarrow 1{ }^{1} A^{\prime}$ 
transition of $\mathrm{C}_{3} \mathrm{H}^{-}$, while the $604 \mathrm{~nm}$ valence $2{ }^{1} A^{\prime \prime} \leftarrow 1{ }^{1} A^{\prime}$ transition is within $10 \mathrm{~nm}$ of more than a dozen known DIBs (Jenniskens \& Desert 1994; Jenniskins \& Désert 1995).

\section{Acknowledgements}

RCF was funded for this work partly by the NASA Postdoctoral Program administered through Oak Ridge Associated Universities. Funding for this work has also come from the U.S. National Science Foundation: award CHE-1058420 and a Multi-User Chemistry Research Instrumentation and Facility (CRIF:MU) award CHE-0741927 and by the Virginia Space Grant Consortium in the form of a Graduate Research Fellowship for RCF. The figures were generated in part with the CheMVP program made available by Dr. Andrew Simmonett of the University of Georgia. RCF would like to thank Dr. David Woon of the University of Illinois for discussions regarding the bonding of the higher row atoms and Dr. Fabio Carelli of Spienza-University of Rome for insights into the nature of electronic excitations and binding in anions. Dr. Timothy J. Lee of the NASA Ames Research Center is also due thanks for his encouragement on finalizing this project. A tremendous debt of gratitude belongs to Prof. T. Danial Crawford of Virginia Tech for providing the computer resources necessary to execute the computations as well as for guiding many aspects of this research and for assistance in editing the manuscript. 


\section{REFERENCES}

2010, CFOUR, a quantum chemical program package written by J.F. Stanton, J. Gauss, M.E. Harding, P.G. Szalay with contributions from A.A. Auer, R.J. Bartlett, U. Benedikt, C. Berger, D.E. Bernholdt, Y.J. Bomble, O. Christiansen, M. Heckert, O. Heun, C. Huber, T.-C. Jagau, D. Jonsson, J. Jusélius, K. Klein, W.J. Lauderdale, D.A. Matthews, T. Metzroth, D.P. O’Neill, D.R. Price, E. Prochnow, K. Ruud, F. Schiffmann, S. Stopkowicz, A. Tajti, J. Vázquez, F. Wang, J.D. Watts and the integral packages MOLECULE (J. Almlöf and P.R. Taylor), PROPS (P.R. Taylor), ABACUS (T. Helgaker, H.J. Aa. Jensen, P. Jørgensen, and J. Olsen), and ECP routines by A. V. Mitin and C. van Wüllen. For the current version, see http://www.cfour.de.

Ard, S., Garrett, W. R., Compton, R. N., Adamowicz, L., \& Stepanian, S. G. 2009, Chem. Phys. Lett., 473, 223

Binkley, J. S., \& Thorne, L. R. 1983, J. Chem. Phys., 79, 2932

Bourissou, D., Guerret, O., Gabbaï, F. P., \& Bertrand, G. 2000, Chem. Rev., 100, 39

Brinkman, E. A., Gunther, E., Schafer, O., \& Brauman, J. I. 1993, J. Chem. Phys., 100, 1840

Brown, E. C., \& Borden, W. T. 2000, Organometallics, 19, 2208

Chen, E. S., \& Chen, E. C. M. 2001, Biochem. Biophys. Res. Commun., 289, 421

Chesnut, D. B. 2002, Heteroat. Chem., 13, 53

Cordiner, M. A., \& Sarre, P. J. 2007, Astron. Astrophys., 472, 537

Coulson, C. A., \& Walmsley, M. 1967, Proc. Phys. Soc., 91, 31 
Crawford, O. H., \& Dalgarno, A. 1967, Chem. Phys. Lett., 1, 23

Crawford, O. H., \& Garrett, W. R. 1977, J. Chem. Phys., 66, 4968

Crawford, T. D., Sherrill, C. D., Valeev, E. F., et al. 2007, J. Comput. Chem., 28, 1610

Driess, M., \& Grützmacher, H. 1996, Angew. Chem. Int. Ed. Engl., 35, 828

Dubois, I. 1968, Can. J. Phys., 46, 2485

Dunning, T. H. 1989, J. Chem. Phys., 90, 1007

Dunning, T. H., Peterson, K. A., \& Wilson, A. K. 2001, J. Chem. Phys., 114, 9244

Fermi, E., \& Teller, E. 1947, Phys. Rev., 72, 399

Fortenberry, R. C., \& Crawford, T. D. 2011a, J. Phys. Chem. A, 115, 8119

—. 2011b, J. Chem. Phys., 134, 154304

Fortenberry, R. C., Crawford, T. D., \& Lee, T. J. 2013, Astrophys. J., 762, 121

Gauss, J., Stanton, J. F., \& Bartlett, R. J. 1991, J. Chem. Phys., 95, 2623

Gutowski, M., Skurksi, P., Boldyrev, A. I., Simons, J., \& Jordan, K. D. 1996, Phys. Rev., 54,1906

Gutsev, G., \& Adamowicz, A. 1995, Chem. Phys. Lett., 235, 377

Helgaker, T., Ruden, T. A., Jørgensen, P., Olsen, J., \& Klopper, W. 2004, J. Phys. Org. Chem., 17, 913

Inostroza, N., \& Senent, M. L. 2010, J. Chem. Phys., 133, 184107

Jenniskens, P., \& Desert, F.-X. 1994, Astron. Astrophys. Supp. Ser., 106, 39 
Jenniskins, P., \& Désert, F.-X. 1995, in The Diffuse Interstellar Bands (Dordrecht, Netherlands: Kluwer), 39-52

Joblin, C., Maillard, J. P., D’Hendecourt, L., \& Léger, A. 1990, Nature, 346, 729

Jochnowitz, E. B., \& Maier, J. P. 2008, Ann. Rev. Phys. Chem., 59, 519

Jordan, K. D., \& Luken, W. 1976, J. Chem. Phys., 64, 2760

Jordan, K. D., \& Wang, F. 2003, Ann. Rev. Phys. Chem., 54, 367

Kutzelnigg, W. 1984, Angew. Chem. Int. Ed. Engl., 23, 272

Leboeuf, M., Russo, N., Salahub, D. R., \& Toscano, M. 1995, J. Chem. Phys., 103, 7413

Lee, T. J., \& Rendell, A. P. 1991, J. Chem. Phys., 94, 6229

Lee, T. J., \& Scuseria, G. E. 1995, in Quantum Mechanical Electronic Structure Calculations with Chemical Accuracy, ed. S. R. Langhoff (Dordrecht: Kluwer Academic Publishers), 47-108

Li, S., Van Zee, R. J., Weltner, W., \& Raghavachari, K. 1995, Chem. Phys. Lett., 243, 275

Linnartz, H., Wehres, N., Walker, G. A. H., et al. 2010, Astron. Astrophys., 511, L3

Lykke, K. R., Neumark, D. M., Andersen, T., Trapa, V. J., \& Lineberger, W. C. 1987, J. Chem. Phys., 87, 6842

Maier, J. P. 1998, J. Phys. Chem., 102, 3462

Maier, J. P., Walker, G. A. H., Bohlender, D. A., et al. 2011, Astrophys. J., 726, 41

Marsh, C. M. B., Hamilton, T. P., Xie, Y., \& Schaefer III, H. F. 1992, J. Chem. Phys., 96, 5310 
Mead, R. D., Lykke, K. R., \& Lineberger, W. C. 1984, J. Chem. Phys., 81, 4883

Meloni, G., Sheehan, S. M., Ferguson, M. J., \& Neumark, D. M. 2004, J. Phys. Chem. A., 108,9750

Monkhorst, H. J. 1977, Int. J. Quantum Chem. Symp., 11, 421

Mukherjee, D., \& Mukherjee, P. K. 1979, Chem. Phys., 39, 325

Mullin, A. S., Murray, K. K., Schulz, C. P., \& Lineberger, W. C. 1993, J. Phys. Chem., 97, 10281

Mullin, A. S., Murray, K. K., Schulz, C. P., Szaflarski, D. M., \& Lineberger, W. C. 1992, Chem. Phys., 166, 207

Ochsenfeld, C., Kaiser, R. I., Lee, Y. T., Suits, A. G., \& Head-Gordon, M. 1997, J. Chem. Phys., 106, 4141

Owens, Z. T., Larkin, J. D., \& Schaefer III, H. F. 2006, J. Chem. Phys., 125, 164322

Pachkov, M., Pino, T., Tulej, M., \& Maier, J. P. 2001, Mol. Phys., 99, 1397

Peterson, K. A., \& Dunning, T. H. 1995, J. Chem. Phys., 102, 2032

Pino, T., Pachkov, M., Tulej, M., et al. 2004, Mol. Phys., 102, 1881

Power, P. P. 1999, Chem. Rev., 99, 3463

Raghavachari, K., Trucks., G. W., Pople, J. A., \& Head-Gordon, M. 1989, Chem. Phys. Lett., 157, 479

Reilly, N. J., Kokkin, D. L., Zhuang, X., et al. 2012, J. Chem. Phys., 136, 194307

Reinemann, D. N., Wright, A. M., Wolfe, J. D., Tschumper, G. S., \& Hammer, N. I. 2011, J. Phys. Chem. A, 115, 6426 
Sams, R. L., Xantheas, S. S., \& Blake, T. A. 2012, J. Phys. Chem. A, 116, 3124

Sarre, P. J. 2000, Mon. Not. R. Astron. Soc., 313, L14

—. 2006, J. Mol. Spectrosc., 238, 1

Scheiner, A. C., Scuseria, G. E., Rice, J. E., Lee, T. J., \& Schaefer III, H. F. 1987, J. Chem. Phys., 87, 5361

Shaik, S., Danovitch, D., Wu, W., et al. 2012, Nat. Chem., 4, 195

Shapley, W. A., \& Bacsky, G. B. 1998, Theor. Chem. Acc., 100, 212

—. 1999, J. Phys. Chem. A, 103, 4505

Shavitt, I., \& Bartlett, R. J. 2009, Many-Body Methods in Chemistry and Physics: MBPT and Coupled-Cluster Theory (Cambridge: Cambridge University Press)

Sheehan, S. M., Parsons, B. F., Zhou, J., et al. 2008, J. Chem. Phys., 128, 034301

Simons, J. 2008, J. Phys. Chem. A., 112, 6401

—. 2011, Annu. Rev. Phys. Chem., 62, 107

Skurski, P., \& Gutowski, M. 2000, J. Mol. Struct., 531, 339

Skurski, P., Gutowski, M., \& Simons, J. 2000, Int. J. Quant. Chem., 80, 1024

Sobczyk, M., Skurski, P., \& Simons, J. 2003, J. Phys. Chem. A, 107, 7084

Stanton, J. F., \& Bartlett, R. J. 1993, J. Chem. Phys., 98, 7029

Stanton, J. F., \& Gauss, J. 1994, J. Chem. Phys., 101, 8938

Takahashi, J., \& Yamashita, K. 1996, J. Chem. Phys., 104, 6613 
Tao, Y. 2005, J. Nat. Sci. Heilongjiang Univ., 22, 241

Thorne, L. R., Suenram, R. D., \& Lovas, F. J. 1983, J. Chem. Phys., 78, 167

Turner, J. E. 1977, Am. J. Phys., 45, 758

Turner, J. E., \& Fox, K. 1966, Phys. Lett., 23, 547

Venkatasubramanian, R., \& Krishnamachari, S. L. N. G. 1991, Indian J. Pure Appl. Phys., 29,697

Wang, F., \& Jordan, K. D. 2002, J. Chem. Phys., 116, 6973

Watts, J. D., Gauss, J., \& Bartlett, R. J. 1992, Chem. Phys. Lett., 200, 1

Woon, D. E., \& Dunning, T. H. 2009, J. Phys. Chem. A, 113, 7915

—. 2010, J. Phys. Chem. A, 114, 8845

—. 2011, J. Comput. Theor. Chem., 963, 7

Yamaguchi, Y., Rienstra-Kiracofe, J. C., Stephens, J. C., \& Schaefer III, H. F. 1998, Chem. Phys. Lett., 291, 509

Zhoa, Z.-X., Hou, C.-Y., Shu, X., Zhang, H.-X., \& Sun, C. 2009, Theor. Chem. Acc., 124, 85

This manuscript was prepared with the AAS IATEX macros v5.2. 
Table 1: Dipole moments of the corresponding neutral radical (in Debye), adiabatic electron binding energies (in $\mathrm{eV}$ ), and singlet adiabatic excited-state transition energies (in $\mathrm{eV}$ ) and wavelengths (in $\mathrm{nm}$ ) for several second-row anions.

\begin{tabular}{|c|c|c|c|c|c|c|}
\hline \multirow[b]{2}{*}{ Molecule } & \multicolumn{2}{|c|}{ Radical Dipole Moment } & \multirow[b]{2}{*}{$\mathrm{eBE}^{b}$} & \multirow[b]{2}{*}{ Transition } & \multicolumn{2}{|c|}{ Transition $^{c}$} \\
\hline & This Work $^{a}$ & Previous & & & Energy & Wavelength \\
\hline \multirow[t]{2}{*}{$\overline{\mathrm{CH}_{2} \mathrm{ON}^{-}}$} & 2.335 & $\ldots$ & $0.46^{d}$ & $22^{1} A \leftarrow 1^{1} A$ & $\begin{array}{c}0.89 \\
\end{array}$ & 13996 \\
\hline & & & & $3^{1} A \leftarrow 1{ }^{1} A$ & 1.08 & 1149 \\
\hline \multirow{2}{*}{$\mathrm{CH}_{2} \mathrm{SN}^{-}$} & 2.703 & $\ldots$ & 1.98 & $2^{1} A^{\prime} \leftarrow 1^{1} A^{\prime}$ & 1.95 & 634 \\
\hline & & & & $1^{1} A^{\prime \prime} \leftarrow 1^{1} A^{\prime}$ & 2.14 & 580 \\
\hline $\mathrm{CH}_{2} \mathrm{NO}^{-e}$ & 2.317 & $\ldots$ & 1.42 & $2{ }^{1} A^{\prime} \leftarrow 1^{1} A^{\prime}$ & 1.55 & 799 \\
\hline \multirow[t]{2}{*}{$\mathrm{CH}_{2} \mathrm{PO}^{-}$} & 2.477 & $\ldots$ & 2.82 & $1^{1} A^{\prime \prime} \leftarrow 1^{1} A^{\prime}$ & 2.89 & 429 \\
\hline & & & & $2{ }^{1} A^{\prime} \leftarrow 1^{1} A^{\prime}$ & 3.08 & 403 \\
\hline \multirow[t]{2}{*}{$\mathrm{C}_{3} \mathrm{H}^{-}$} & 3.409 & $3.163^{f}$ & 1.83 & $1^{1} A^{\prime \prime} \leftarrow 1^{1} A^{\prime}$ & 0.93 & 1328 \\
\hline & & & & $2{ }^{1} A^{\prime} \leftarrow 1^{1} A^{\prime}$ & 2.05 & 604 \\
\hline \multirow[t]{2}{*}{$\mathrm{CCSiH}^{-}$} & & $\cdots$ & 3.11 & $1^{1} A^{\prime \prime} \leftarrow 1^{1} A^{\prime}$ & 2.06 & 602 \\
\hline & & & & $2^{1} A^{\prime} \leftarrow 1^{1} A^{\prime}$ & 3.23 & 384 \\
\hline $\mathrm{CCOH}^{-e}$ & 4.401 & $4.410^{g}$ & 2.52 & $1^{1} A^{\prime \prime} \leftarrow 1^{1} A^{\prime}$ & 2.43 & 511 \\
\hline $\mathrm{CCSH}^{-}$ & 4.492 & $\ldots$ & 2.86 & $1^{1} A^{\prime \prime} \leftarrow 1^{1} A^{\prime}$ & $2.82^{d}$ & 440 \\
\hline $\mathrm{CCNH}_{2}^{-}$ & 5.903 & $\ldots$ & 1.97 & $1^{1} B_{1} \leftarrow 1^{1} A^{\prime}$ & 2.00 & 620 \\
\hline $\mathrm{CCPH}_{2}^{-}$ & 4.759 & & 3.21 & $2^{1} A^{\prime} \leftarrow 1^{1} A^{\prime}$ & 3.16 & 392 \\
\hline $\mathrm{BH}_{3} \mathrm{NH}_{2}^{-}$ & 2.524 & . & 2.28 & $2{ }^{1} A^{\prime} \leftarrow 1^{1} A^{\prime}$ & 2.53 & 490 \\
\hline $\mathrm{BH}_{3} \mathrm{PH}_{2}^{-}$ & 2.889 & $\ldots$ & 2.74 & $2{ }^{1} A^{\prime} \leftarrow 1^{1} A^{\prime}$ & 2.78 & 446 \\
\hline \multirow[t]{2}{*}{$\mathrm{AlH}_{3} \mathrm{NH}_{2}^{-}$} & 2.579 & & 3.22 & $2{ }^{1} A^{\prime} \leftarrow 1^{1} A^{\prime}$ & 3.17 & 391 \\
\hline & & & & $1^{1} A^{\prime \prime} \leftarrow 1^{1} A^{\prime}$ & 3.32 & 373 \\
\hline \multirow[t]{2}{*}{$\mathrm{AlH}_{3} \mathrm{PH}_{2}^{-}$} & 2.167 & $\ldots$ & 3.25 & $2{ }^{1} A^{\prime} \leftarrow 1^{1} A^{\prime}$ & 3.21 & 387 \\
\hline & & & & $1^{1} A^{\prime \prime} \leftarrow 1^{1} A^{\prime}$ & 3.35 & 370 \\
\hline
\end{tabular}

${ }^{\bar{a}}$ UHF-CCSD/aug-cc-pVTZ values for the radicals at the UHF-CCSD(T)/aug-cc-pVTZ geometries. ${ }^{b}$ The differences between the RHF- (anion) and UHF- (radical) CCSD(T)/augcc-pVTZ energies. ${ }^{c}$ Adiabatic EOM-CCSD/d-aug-cc-pVDZ values. ${ }^{d}$ This value is from the non-minimum geometry but functions as an upper bound estimate. ${ }^{e}$ Computed by Fortenberry \& Crawford (2011b). ${ }^{f} \mathrm{CASSCF} / \mathrm{D} 95(\mathrm{~d}, \mathrm{p})$ computation from Takahashi \& Yamashita (1996). ${ }^{g}$ CISD/TZ3P(2f,2d) result from Yamaguchi et al. (1998). 
Table 2: EOM-CCSD vertical excitation energies (in eV), oscillator strengths, ${ }^{a}$ and vertical electron binding energies (in eV) from ground state CCSD(T)/aug-cc-pVTZ geometries for several basis sets. ${ }^{b}$

\begin{tabular}{|c|c|c|c|c|c|c|c|c|c|c|}
\hline Molecule & Transition & pVDZ & apVDZ & dapVDZ & tapVDZ & $\mathrm{pVTZ}$ & apVTZ & dapVTZ & $f$ & $\mathrm{eBE}^{c}$ \\
\hline \multirow[t]{2}{*}{$\mathrm{CH}_{2} \mathrm{ON}^{-}$} & $2^{1} A \leftarrow 1^{1} A$ & 3.82 & 1.82 & 1.17 & 1.03 & 3.54 & 1.90 & 1.37 & $1 \times 10^{-3}$ & \multirow[t]{2}{*}{1.53} \\
\hline & $3^{1} A \leftarrow 1^{1} A$ & 1.26 & 1.13 & 1.07 & 1.06 & 1.21 & 1.10 & 1.08 & $7 \times 10^{-3}$ & \\
\hline \multirow[t]{2}{*}{$\mathrm{CH}_{2} \mathrm{SN}^{-}$} & $2^{1} A^{\prime} \leftarrow 1^{1} A^{\prime}$ & 5.95 & 3.18 & 2.09 & 1.95 & 5.81 & 3.19 & 2.29 & $5 \times 10^{-3}$ & \multirow[t]{2}{*}{2.24} \\
\hline & $1^{1} A^{\prime \prime} \leftarrow 1^{1} A^{\prime}$ & 2.76 & 2.64 & 2.43 & 2.04 & 2.73 & 2.64 & 2.56 & $1 \times 10^{-2}$ & \\
\hline $\mathrm{CH}_{2} \mathrm{NO}^{-}$ & $2^{1} A^{\prime} \leftarrow 1^{1} A^{\prime}$ & 6.85 & 2.88 & 1.77 & 1.63 & 6.31 & 2.86 & 1.94 & $3 \times 10^{-3}$ & 2.13 \\
\hline \multirow[t]{2}{*}{$\mathrm{CH}_{2} \mathrm{PO}^{-}$} & $1^{1} A^{\prime \prime} \leftarrow 1^{1} A^{\prime}$ & 6.44 & 3.48 & 2.89 & 2.79 & 6.24 & 3.47 & 2.96 & $2 \times 10^{-3}$ & \multirow[t]{2}{*}{2.79} \\
\hline & $2^{1} A^{\prime} \leftarrow 1^{1} A^{\prime}$ & 5.37 & 4.70 & 3.05 & 2.81 & 5.19 & 4.65 & 3.43 & $1 \times 10^{-4}$ & \\
\hline \multirow[t]{2}{*}{$\mathrm{C}_{3} \mathrm{H}^{-}$} & $1^{1} A^{\prime \prime} \leftarrow 1^{1} A^{\prime}$ & 1.21 & 1.15 & 1.14 & 1.14 & 1.17 & 1.14 & 1.13 & $2 \times 10^{-3}$ & \multirow[t]{2}{*}{2.34} \\
\hline & $2^{1} A^{\prime} \leftarrow 1^{1} A^{\prime}$ & 6.38 & 3.01 & 2.46 & 2.37 & 5.68 & 3.03 & 2.61 & $3 \times 10^{-3}$ & \\
\hline \multirow[t]{2}{*}{$\mathrm{CCSiH}^{-}$} & $1^{1} A^{\prime \prime} \leftarrow 1^{1} A^{\prime}$ & 2.09 & 2.05 & 2.05 & 2.05 & 2.11 & 2.07 & 2.07 & $1 \times 10^{-2}$ & \multirow[t]{2}{*}{3.27} \\
\hline & $2^{1} A^{\prime} \leftarrow 1^{1} A^{\prime}$ & 6.40 & 4.02 & 3.32 & 3.26 & 6.00 & 3.92 & 3.45 & $2 \times 10^{-2}$ & \\
\hline $\mathrm{CCOH}^{-d}$ & $1^{1} A^{\prime \prime} \leftarrow 1^{1} A^{\prime}$ & 4.85 & 2.92 & 2.68 & 2.66 & 4.47 & 2.99 & 2.82 & $3 \times 10^{-3}$ & 2.76 \\
\hline $\mathrm{CCSH}^{-}$ & $1^{1} A^{\prime \prime} \leftarrow 1^{1} A^{\prime}$ & 4.59 & 3.26 & 2.92 & 2.88 & 4.44 & 3.31 & 3.06 & $2 \times 10^{-3}$ & 2.94 \\
\hline $\mathrm{CCNH}_{2}^{-}$ & $2^{1} A^{\prime} \leftarrow 1^{1} A^{\prime}$ & 4.74 & 2.59 & 2.36 & 2.31 & 4.24 & 2.66 & 2.47 & $1 \times 10^{-4}$ & 2.42 \\
\hline $\mathrm{CCPH}_{2}^{-}$ & $2^{1} A^{\prime} \leftarrow 1^{1} A^{\prime}$ & 6.82 & 4.59 & 3.72 & 3.27 & 6.11 & 4.56 & 3.44 & $2 \times 10^{-3}$ & 3.30 \\
\hline $\mathrm{BH}_{3} \mathrm{PH}_{2}^{-}$ & $2^{1} A^{\prime} \leftarrow 1^{1} A^{\prime}$ & 6.51 & 3.88 & 3.35 & 3.26 & 5.93 & 3.89 & 3.41 & $3 \times 10^{-3}$ & 3.26 \\
\hline \multirow[t]{2}{*}{$\mathrm{AlH}_{3} \mathrm{NH}_{2}^{-}$} & $2^{1} A^{\prime} \leftarrow 1^{1} A^{\prime}$ & $-^{e}$ & 3.99 & 3.70 & 3.69 & - & 4.05 & 3.86 & $1 \times 10^{-2}$ & \multirow[t]{2}{*}{3.80} \\
\hline & $1^{1} A^{\prime \prime f} \leftarrow 1^{1} A^{\prime}$ & 7.25 & 4.56 & 3.98 & 3.85 & 6.88 & 4.60 & 4.13 & $1 \times 10^{-5}$ & \\
\hline \multirow[t]{2}{*}{$\mathrm{AlH}_{3} \mathrm{PH}_{2}^{-}$} & $2^{1} A^{\prime} \leftarrow 1^{1} A^{\prime}$ & $-^{e}$ & 4.22 & 3.84 & 3.80 & - & 4.27 & 3.96 & $2 \times 10^{-2}$ & \multirow[t]{2}{*}{3.85} \\
\hline & $1^{1} A^{\prime \prime f} \leftarrow 1^{1} A^{\prime}$ & 7.38 & 4.69 & 4.03 & 3.86 & 7.04 & 4.70 & 4.16 & $1 \times 10^{-3}$ & \\
\hline
\end{tabular}

${ }^{a}$ Oscillator strengths $\left(f\right.$ values) reported are for CCSD/d-aug-cc-pVTZ. ${ }^{b}$ Dunning's correlation consistent basis sets are abbreviated, e.g. t-aug-cc-pVDZ is tapVDZ. ${ }^{c}$ Computed with EOMIP-CCSD/t-aug-cc-pVDZ. ${ }^{d}$ Computed by Fortenberry \& Crawford (2011b). ${ }^{e}$ No clear correspondence between the pVDZ/pVTZ results and those with more diffuse basis sets could be established.

${ }^{f}$ Part of a degenerate set of $4 p$ Rydberg-like states. 

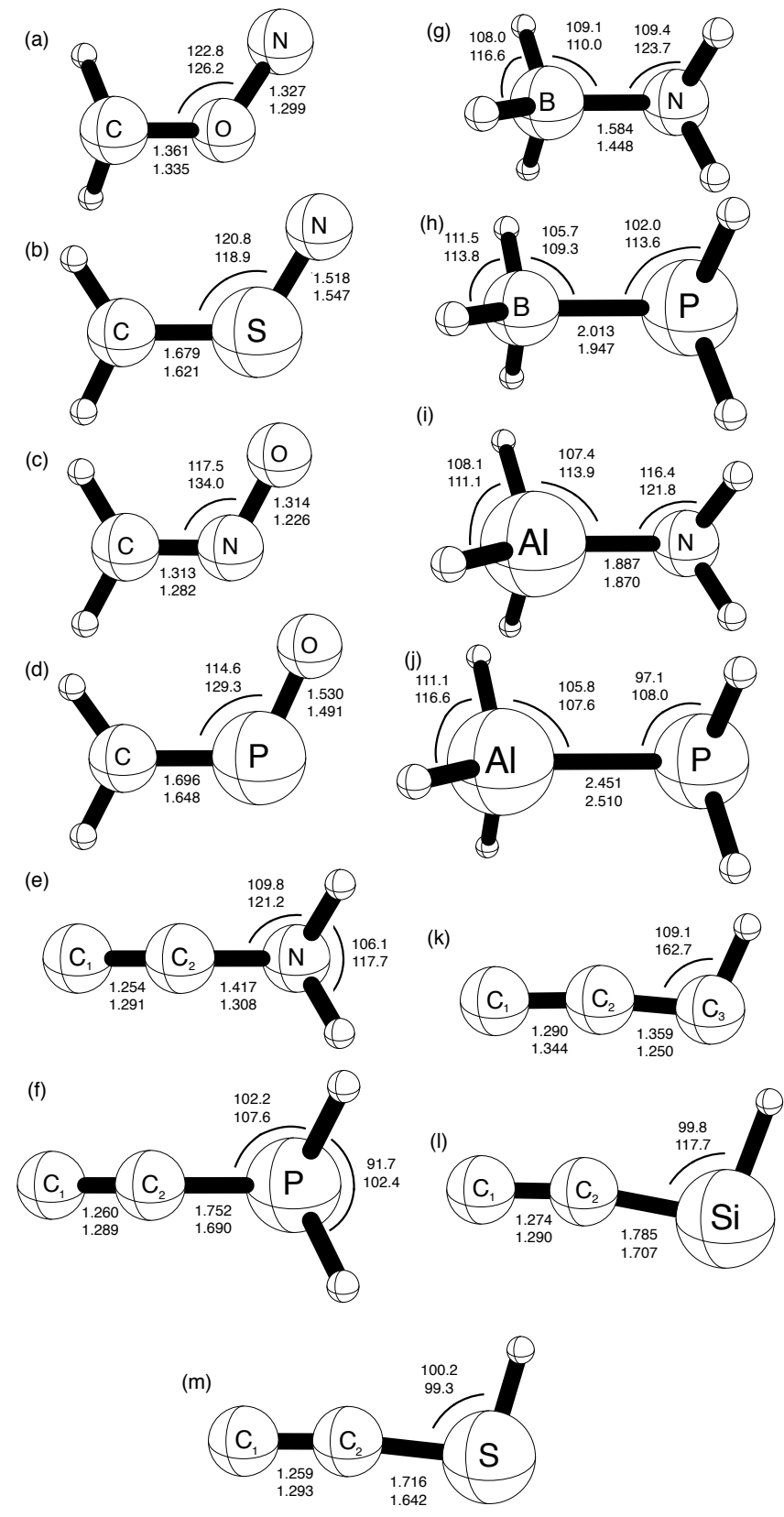

Fig. 1. - CCSD(T)/aug-cc-pVTZ optimized structures of the ground states of the closedshell anions (top values; in units of $\AA$ and degrees) and neutral radicals (bottom values) of: (a) $1^{1} A \mathrm{CH}_{2} \mathrm{ON}^{-}$\& approximate (see text) $1^{2} A \mathrm{CH}_{2} \mathrm{ON}$; (b) $1^{1} A^{\prime} \mathrm{CH}_{2} \mathrm{SN}^{-} \& 1^{2} A^{\prime} \mathrm{CH}_{2} \mathrm{SN}$; (c) $1^{1} A^{\prime} \mathrm{CH}_{2} \mathrm{NO}^{-} \& 1^{2} A^{\prime} \mathrm{CH}_{2} \mathrm{NO}$; (d) $1^{1} A^{\prime} \mathrm{CH}_{2} \mathrm{PO}^{-} \& 1^{2} A^{\prime} \mathrm{CH}_{2} \mathrm{PO}$; (e) $1{ }^{1} A^{\prime} \mathrm{CCNH}_{2}^{-}$ $\left(\angle \mathrm{CCN}=177.8^{\circ}\right) \& 1^{2} B_{1} \mathrm{CCNH}_{2} ;$ (f) $1^{1} A^{\prime} \mathrm{CCPH}_{2}^{-}\left(\angle \mathrm{CCP}=171.1^{\circ}\right) \& 1^{2} A^{\prime} \mathrm{CCPH}_{2}$ $\left(\angle \mathrm{CCP}=175.6^{\circ}\right)$; (g) $1^{1} A^{\prime} \mathrm{BH}_{3} \mathrm{NH}_{2}^{-} \& 1^{2} A^{\prime \prime} \mathrm{BH}_{3} \mathrm{NH}_{2}$; (h) $1^{1} A^{\prime} \mathrm{BH}_{3} \mathrm{PH}_{2}^{-} \& 1^{2} A^{\prime} \mathrm{BH}_{3} \mathrm{PH}_{2}$; (i) $1^{1} A^{\prime} \mathrm{AlH}_{3} \mathrm{NH}_{2}^{-} \& 1^{2} A^{\prime} \mathrm{AlH}_{3} \mathrm{NH}_{2}$; (j) $1^{1} A^{\prime} \mathrm{AlH}_{3} \mathrm{PH}_{2}^{-} \& 1^{2} A^{\prime} \mathrm{AlH}_{3} \mathrm{PH}_{2}$; (k) $1^{1} A^{\prime} \mathrm{C}_{3} \mathrm{H}^{-}$ $\left(\angle \mathrm{CCC}=174.2^{\circ}\right) \& 1^{2} A^{\prime} \mathrm{C}_{3} \mathrm{H}\left(\angle \mathrm{CCC}=175.7^{\circ}\right)$; (l) $1^{1} A^{\prime} \mathrm{CCSiH}^{-}\left(\angle \mathrm{CCSi}=170.2^{\circ}\right) \&$ $1^{2} A^{\prime} \mathrm{CCSiH}\left(\angle \mathrm{CCSi}=161.4^{\circ}\right)$; and $(\mathrm{m}) 1^{1} A^{\prime} \mathrm{CCSH}^{-}\left(\angle \mathrm{CCS}=173.9^{\circ}\right) \& 1^{2} A^{\prime \prime} \mathrm{CCSH}$ $\left(\angle \mathrm{CCS}=172.7^{\circ}\right)$. 

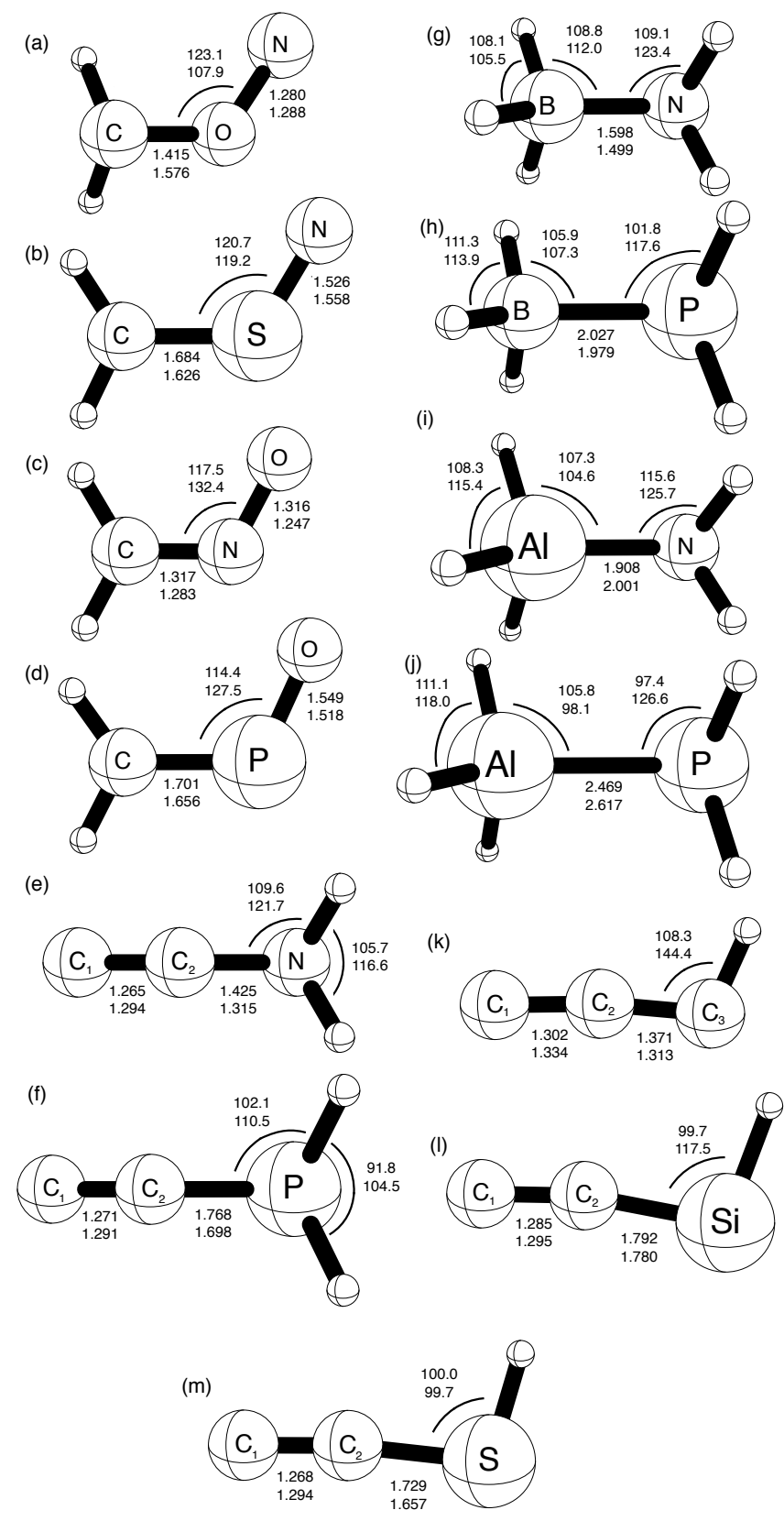

Fig. 2.- CCSD/d-aug-cc-pVDZ optimized structures of ground (top values; again in $\AA$ and degrees) and first excited states (bottom values) of: (a) $1^{1} A \& 2{ }^{1} A \mathrm{CH}_{2} \mathrm{ON}^{-}$; (b) $1^{1} A^{\prime} \& 2{ }^{1} A^{\prime} \mathrm{CH}_{2} \mathrm{SN}^{-}$; (c) $1{ }^{1} A^{\prime} \& 2^{1} A^{\prime} \mathrm{CH}_{2} \mathrm{NO}^{-}$; (d) $1{ }^{1} A^{\prime} \& 2^{1} A^{\prime} \mathrm{CH}_{2} \mathrm{PO}^{-}$; (e) $1^{1} A^{\prime} \mathrm{CCNH}_{2}^{-}\left(\angle \mathrm{CCN}=177.9^{\circ}\right) \& 1^{1} B_{1} \mathrm{CCNH}_{2}^{-}$; (f) $1^{1} A^{\prime}\left(\angle \mathrm{CCP}=170.5^{\circ}\right) \& 2{ }^{1} A^{\prime}$ $\mathrm{CCPH}_{2}^{-}\left(\angle \mathrm{CCP}=169.4^{\circ}\right) ;(\mathrm{g}) 1^{1} A^{\prime} \& 2^{1} A^{\prime} \mathrm{BH}_{3} \mathrm{NH}_{2}^{-}$; (h) $1^{1} A^{\prime} \& 2^{1} A^{\prime} \mathrm{BH}_{3} \mathrm{PH}_{2}^{-}$; (i) $1^{1} A^{\prime} \& 2{ }^{1} A^{\prime} \mathrm{AlH}_{3} \mathrm{NH}_{2}^{-}$; (j) $1{ }^{1} A^{\prime} \& 2^{1} A^{\prime} \mathrm{AlH}_{3} \mathrm{PH}_{2}^{-} ;(\mathrm{k}) 1^{1} A^{\prime} \mathrm{C}_{3} \mathrm{H}^{-} \quad\left(\angle \mathrm{CCC}=174.0^{\circ}\right)$ $\& 1^{1} A^{\prime \prime} \mathrm{C}_{3} \mathrm{H}^{-}\left(\angle \mathrm{CCC}=174.0^{\circ}\right)$; (l) $1^{1} A^{\prime} \mathrm{CCSiH}^{-}\left(\angle \mathrm{CCSi}=169.4^{\circ}\right) \& 1^{1} A^{\prime \prime} \mathrm{CCSiH}^{-}$ $\left(\angle \mathrm{CCSi}=170.5^{\circ}\right)$; and $(\mathrm{m}) 1^{1} A^{\prime} \mathrm{CCSH}^{-}\left(\angle \mathrm{GCS}=173.3^{\circ}\right) \&$ approximate (see text) $1^{1} A^{\prime \prime}$ $\mathrm{CCSH}^{-}\left(\angle \mathrm{CCS}=173.6^{\circ}\right)$. 